\title{
A LITERATURA AFRO-BRASILEIRA E AFRICANA, CAMINHO PARA IMPLEMENTAÇÃO DA LEI 10.639/03
}

\author{
Romilda Oliveira Santos ${ }^{\mathrm{i}}$
}

\section{Considerações Iniciais}

Tendo em vista que após dez anos de vigência a Lei 10.639/03 ainda enfrenta dificuldades em sua implementação, visto que esbarra muitas vezes no desconhecimento de muitos professores a respeito de como tratar o Ensino da Historia e Cultura Africana e Afrobrasileira na Educação Básica. O principal objetivo desse artigo é apontar alguns caminhos que possam colaborar para a melhoria das práticas pedagógicas em salas de aula da Rede Pública de Ensino. Pretende-se, portanto, apresentar uma experiência de implementação de atividades de ensino deste tema.

As diversas influências culturais que permeiam a sociedade brasileira necessitam de novas reflexões sobre o como agir na formação sistemática desenvolvida pela escola pública afim de formar seres humanos mais críticos e mais tolerantes nos relacionamentos sociais dessa contemporaneidade. O presente artigo pretende refletir sobre e como ações em salas de aula podem contribuir para a implementação da Lei 10.639/03, no que toca especificamente à obrigatoriedade do Ensino da Historia e Cultura Africana e Afro-brasileira na Educação Básica.

O artigo além de apresentar algumas sugestões para o trabalho com a literatura afrobrasileira e africana, traz o relato, de uma sequencia de ações desenvolvidas em sala de aulas com alunos de 14 a 17 anos do primeiro ano do ensino médio de uma escola pública, na região metropolitana da capital do Paraná. O objetivo era levá-los a refletir sobre as ações do cotidiano escolar tendo em vista atitudes de discriminação e racismo que criavam um sentimento de baixa-estima em alunos afrodescendentes e negros, levando-os muitas vezes a abandonarem a escola, acreditando-se incapazes de aprender.

O projeto foi fundamentado em teorias da aprendizagem e no trabalho com a literatura africana e afro-brasileira para desconstruir estereótipos negativos, presentes no imaginário dos alunos e consequentemente, da população brasileira, sobre a etnia negra. O projeto foi transformado em material pedagógico cujos passos detalhados da execução das ações levaram ao alcance dos objetivos pensados e propostos. 
O pensamento norteador do trabalho é sugerir o desenvolvimento de ações que contribuam para a afirmação do orgulho de pertencimento a etnia negra e à afirmação do conhecimento historicamente acumulado que os alunos afrodescendentes e negros trazem como vivência.

A literatura afro-brasileira e africana é o caminho para a construção de novos olhares sobre as origens da etnia negra no Brasil e seus descendentes.

\section{Problemática e fundamentação teórica.}

A construção de um "novo olhar" para o diferente. Respeito aos diversos costumes, tradições e cultura presentes numa mesma sociedade. O reconhecimento e a valorização das contribuições culturais, literárias e sociais africanas e afro-brasileiras para a formação da sociedade brasileira. A construção de um imaginário positivo das origens do negro e dos afrodescendentes, no plano simbólico. A elevação da autoestima desta etnia, e a consequente redução da evasão escolar.

Antônio A. Cândido diz que a literatura "é a arte que transforma/humaniza o homem e a sociedade. A literatura como produção humana está intrinsecamente ligada à vida social" (1972, p.803-809). A humanização e a transformação do ser "homem" que se concretiza a partir do momento que este homem é capaz de sentir, relacionar e conceber a realidade do outro eu, do outro ser. A literatura contribui para essa humanização, pois os discursos, as vozes e os sujeitos ali presentes nos mostram semelhanças e diferenças, influências positivas ou não, de uma cultura sobre a outra.

O trabalho com literatura africana e afro-brasileira possibilita a construção de laços de troca de tradições, costumes e conhecimento e cultura através do espaço crítico reflexivo da sala de aula. Von Zuben (1994), em seu artigo "Sala de Aula: Da angústia de labirinto à fundação da liberdade, afirma que a sala de aula não é o espaço físico e sim, o espaço imaginário onde se dá a luta entre ideias que contribua para a formação do conhecimento, afirma que

o ser humano tem a necessidade primária de buscar o novo, a liberdade de ser. E é neste "espaço de ação" que a fala dialógica, as ideias sobre fatos, coisas e pessoas se formam e desenvolvem mais intensamente. Este momento cheio de rupturas, vivo e dinâmico do indivíduo apresenta-se imerso de possibilidades e de construção de horizontes de expectativas no tecer da sua historia social. E neste contexto, ainda, que se dá o começo da ação política pela qual se instaura a confirmação do eu pelo outro e deste por aquele, em suma: o diálogo (1994, p.10). 
Para o autor o espaço da sala de aula é o lugar de "evocação e provocação, o evento". É nesse espaço que o ser humano se constrói através da "palavra, das interações sociais. Onde ideias e pensamentos se entrecruzam e estabelecem uma luta com os valores sociais de orientação contraditória" (Bakhtin/Volochinov, 1999, p.123). E neste entrecruzar de opiniões e ideias de um sujeito com o seu outro, o ser humano aprende. Assim, o ser humano frente ao novo faz novas leituras "se transforma, se humaniza através das trocas, das interações e da literatura" (Cândido, 1972, p.806).

Charles S. Peirce, diz que o homem procura dar significado a tudo o que o rodeia inicialmente, através da impressão e do sentimento de puro de prazer. Em seguida, relaciona essa impressão e este sentimento ao seu existir, ao seu entorno. E, inteligentemente relaciona os signos, interpreta e representa o mundo" (Peirce. 1999, pp 369-372).

Hans Robert Jauss (1994), em “A história da literatura como provocação à teoria literária", defende a necessidade de um novo modo de olhar sobre o texto literário. Para ele, "o leitor dialoga com a obra atualizando-a no ato da leitura," e a partir do contexto social e das experiências nas quais está inserido. "O leitor reage de modo particular e individual”, e a forma como reage nas diferentes épocas caracteriza o caráter artístico da obra literária. $\mathrm{O}$ texto literário responde aos questionamentos do leitor através de uma relação dialógica, a partir dos momentos históricos nos quais ambos estão inseridos (o processo histórico da recepção e produção estética).

Jauss (1994) ainda, traz para a discussão o conceito de horizonte de expectativas no qual, afirma que o sujeito está propenso a mudanças e alterações ao se sentir satisfeito em suas expectativas iniciais e contínuas ou seja, ao satisfazer sua primeira expectativa, logo surge outra. Acrescenta que as diferentes interpretações de recepção do passado e do presente, oferecem respostas diferentes a novas perguntas em diálogo com leituras anteriores.

O diálogo entre as recepções provoca rupturas e novos olhares e então, caracteriza-se a função social e emancipadora da literatura. Torna o leitor, sujeito capaz de visualizar aspectos de sua prática cotidiana de modo diferenciado, mobiliza-o para novas maneiras de pensar e agir sobre o mundo.

Wolfgang Iser (1996) afirma, na sua obra, “ O ato da leitura: uma teoria do efeito estético”, o texto é um dispositivo a partir do qual o sujeito constrói suas representações. E que o leitor e as estruturas textuais "estão intimamente ligados, pois estas propiciam à aquele experiências reais de leitura, através da interação, do diálogo entre ambos, no espaço sincrônico e diacrônico". Ainda, segundo Iser (1996, p.73) em “A Teoria do Efeito”, “a leitura é um processo de comunicação, um diálogo de vozes que se entrecruzam no ato da 
leitura: a do autor, do texto e do leitor". O sujeito leitor, nesse processo, torna-se atuante, pois, ao interagir com a estrutura do texto literário, além de sofrer seus efeitos, age sobre eles.

As duas teorias, a Estética da Recepção e a Teoria do Efeito apresentam o leitor como elemento participativo. Concebendo a literatura como provocação, na medida em que conduzem o leitor à busca de novos sentidos, levando-o a uma visão mais ampla e crítica, tanto da obra literária, como de sua própria identidade.

A própria estrutura dos textos ficcionais, permite que o leitor ali inserido, altere seu ponto de vista. Construindo novos horizontes, no momento que preenche as lacunas do texto com sua bagagem de vida, sua vivencia, etc. No diálogo com o texto literário, o homem leitor se transforma. Vygotsky (1998) em seus estudos diz que o professor é responsável em criar o ambiente propicio para a interação pois:

O aprendizado ocorre na ZDP, (Zona de Desenvolvimento Proximal,) pois é aí, em interação com outras pessoas, que a criança vai entrar em contato com coisas que ela desconhece, ao passo que ela, nessa dinâmica é capaz de colocar em movimento várias coisas, as quais, sem a ajuda do outro, seria impossível de ocorrer. (Vygotsky, 1998, p.111)

Segundo o autor quando o aluno entra na escola, ele já possui um conhecimento prévio, já traz para a escola uma bagagem de conhecimentos que adquiriu no decorrer de sua vida. Oferecer textos literários para leitura é, portanto, aprofundar "a capacidade de ampliação de horizontes do pensamento crítico e a sensibilidade estética" (Vygotsky,1998, p.111).

A “construção de fronteiras múltiplas, não apenas para ações internas” (Abdala, 2006, p.19) na sala de aula, como também para as ações externas nas comunidades de pertencimento permitirá que o conhecimento particular não seja subjugado e esquecido, e substituído pelo prisma globalizador de uma cultura hegemônica na qual, o igual é valorizado e valorado.

A literatura é o caminho para o conhecimento do mundo, dos povos, seus costumes e sua história. Abdala (2006, p.19) sugere que é importante fazer sobressair a "potencialidade do sujeito" (individual ou coletivo), procurando interações onde cada participante da interação comunitária (individualmente ou em grupo) seja levado pela prática, a internalizar o fato de que ele é a razão de ser desse processo interativo. A práxis assim entendida reuniria condições de desenhar uma nova persona inclinada a descartar, do ponto de vista crítico, hábitos arraigados desde os tempos coloniais. Abdala ainda considera que a consciência de que os "nós" da vida social, diante de uma concepção de mundo que se organiza em rede, interagem com muitas outras séries discursivas, demandando atualizações situacionais próprias e 
criativas. É nas interações desses campos que se afirma a função social da literatura (Abdala, 2006, p.19).

A diversidade histórica e cultural do povo brasileiro, suas cores e suas nuances permite que teias sejam tecidas através de discussões, debates e reflexões no estudo da literatura afro-brasileira e africana com objetivo de eliminar as leituras de diferentes e exóticos sobre os biótipos brasileiros e africanos. Novas histórias deverão ser contadas e sobre os mais variados prismas num constante criar e recriar de diferentes pontos de vistas fornecendo assim elementos que possibilitam uma visão diferente sobre "o eu e o outro". Assim, o pensar criticamente, sem enfoque no território de raça, nacionalidade e gênero amplia as margens de "conhecimento da mistura étnica sociocultural, dessa imensa pluralidade que envolve o Estado Brasileiro" (Abdala, 2006, p.19).

A valoração desse conhecimento cultural étnico não implica em desconsideração do Estado Nação vigente e das tendências de globalização para o mundo, nesta sociedade contemporânea do conhecimento.

Conteúdos de literatura africana, afro-brasileira e língua materna poderão ser trabalhados através do Método Recepcional, desenvolvido por Bordini e Aguiar (1993, p.88) as sequências didáticas expandidas de Cosson (2006, p.30), tomando como ponto de partida ações afirmativas na construção da autoestima - "que envolve tanto crenças e emoções autossignificantes e expressão de comportamentos- como características de personalidade ou condição psicológica numa dimensão particular ou extensão global” (Sedikides; Greg, 2003, pp.110-138).

Estereótipos negativos sobre o negro e suas origens foram enraizados no imaginário do povo brasileiro. Portanto é necessário desconstruir os modelos propostos por uma sociedade imperialista no passado e construir arquétipos positivos do homem, de sociedade e de mundo.

O estudo não pretende em nenhum momento esgotar um leque tão imenso de possibilidades para o enfoque da "Historia e Cultura Africana e Afro-brasileira". Entretanto espero que possa contribuir com reflexões simples para os primeiros passos em direção à mudança da prática em sala de aula de todos os que se interessarem pelo tema.

O professor poderá usar o método recepcional de Bondini e Aguiar (1993, p.88) e as sequencias expandidas de Rildo Cosson (2006, p.30) para traçar seu plano de trabalho docente. O importante é que siga os passos planejados minuciosamente. 


\section{O método recepcional e o ensino da Historia e Cultura Africana e Afro-brasileira}

O método proposto por Bondini e Aguiar (1993, p.88) consiste em cinco passos básicos: O primeiro passo é "a determinação do horizonte de expectativas". Nesta etapa, o professor faz um levantamento das vivências do aluno e suas preferências. E comece com um texto que contemple o interesse dos alunos, neste momento se dá a recepção do texto e seu reconhecimento, assegurado pela relação dialógica estabelecida entre o autor, a obra e o leitor. Segundo, BORDINI e Aguiar, "às estratégias de ensino, que deverão ser organizadas a partir de procedimentos conhecidos dos alunos e de seu agrado". (Bordini; Aguiar, 1993, p. 88).

A utilização de um questionário impresso com perguntas sobre suas origens, descendências e tradições culturais e como se considera com relação à cor da pele e características físicas, o conhecimento dos mesmos, sobre os termos racismo, auto estima, democracia racial, discriminação racial, biótipo, resistência negra, África, consciência negra. E para completar uma enquete virtual, com cinco tópicos: por exemplo, como eles se consideram em relação à cor da pele, origem familiar, definição da etnia pelas características físicas, momentos na vida brasileira que a cor da pele ou a etnia influencia na vida das pessoas, e quais são suas influências musicais.

O segundo passo é "o atendimento ao horizonte de expectativas": Esta etapa é um pouco mais longa. Os textos apresentados aos alunos devem satisfazer o conhecimento já construído e a visão de mundo alicerçada. O aluno fará uma leitura superficial explicita do texto. Para Bordini e Aguiar

\footnotetext{
Uma vez detectadas as aspirações, valores e familiaridades dos alunos com o tema proposto, a etapa seguinte consiste no atendimento do horizonte de expectativas, ou seja, proporcionar à classe experiências com os textos visuais/literários que satisfaçam as suas necessidades em dois sentidos. Primeiro, quanto ao objeto, uma vez que os textos escolhidos para o trabalho em sala de aula serão aqueles que correspondem ao esperado. Segundo, quanto às estratégias de ensino, que deverão ser organizadas a partir de procedimentos conhecidos dos alunos e de seu agrado. (1993, p.88).
}

Nesta etapa, após a leitura dos textos, promover o debate sobre o(s) tema(s). O professor deve apresentar as regras do debate e como mediador(a) incentivar a produção oral, o relatar e na sequencia apresentar o questionamento sobre o primeiro tema, por exemplo: "O que é ser diferente", "Ações Afirmativas", "Diferenças de Gênero", 
"Diversidade religiosa", "Preconceito Social e Racial", "Racismo", "Discriminação", “África”, “A lei 10.639/03” etc.

O professor deve procurar anotar na lousa as opiniões levantadas durante o debate e ao final procurar saber como e onde os alunos adquiriram estas informações. Na sequência, estabelecer uma conversa mais informal sobre os termos apresentados e ver o conceito e o significado de cada vocábulo. Numa relação dialógica, sugerir uma pesquisa sobre os temas debatidos e a comparação dos registros orais do debate com os novos conceitos pesquisados sempre orientando os alunos a registrarem suas sugestões e conclusões nos cadernos. Produzir vídeo sobre diversidade humana, e diversidade na fauna e na flora, vídeo sobre festas e tradições diferentes de cada povo etc., e apresentar aos alunos, seguido do questionamento sobre: o que é ser diferente? Apresentar fichas previamente preparadas com os conceitos e definições sobre os termos pesquisados e solicitar que os alunos, também os comparem à pesquisa realizada, e, caso necessário complementem ou não, o conteúdo pesquisado.

As redes sociais estão presentes na vida dos jovens adolescentes da contemporaneidade, o professor pode sugerir a criação de um blog para os alunos trocarem informações e opiniões sobre os trabalhos realizados em sala de aula. Este deve ser um momento muito produtivo, pois o interesse demonstrado pelos alunos, os levam a fazerem perguntas sobre o assunto. As anotações no blog permitem que professor possa fazer levantamentos sobre os aspectos linguísticos da produção escrita para o trabalho com a língua materna.

"A ruptura do horizonte de expectativa" é o terceiro passo. Nesta etapa, o professor apresenta algo novo, informações, imagens. É chegado o momento de romper com o conhecimento já adquirido pelo aluno, na sua realidade e no momento de aprendizagem. É este, o momento, para leitura de textos um pouco mais complexos, que provocará o aluno e irá de encontro às suas expectativas, causando até mesmo alguma estranheza, ampliando dessa forma seus conhecimentos, ir além do óbvio, do já conhecido.

"Entretanto, os demais recursos compositivos devem ser radicalmente diferentes, de modo a que o aluno ao mesmo tempo perceba estar ingressando num campo desconhecido, mas também não se sinta inseguro demais e rejeite a experiência”. (Bordini \&Aguiar, 1993, p. 89).

Por exemplo, o professor retoma o termo África, e os questionamentos para identificar o conceito internalizado através do relato espontâneo do aluno. O reconhecimento do tema se dá pela exibição dos vídeos “A África que nunca vimos ou que ninguém nos mostrii a" e "África. Outro olhariii". Ao final da exibição dos vídeos, fazer o levantamento dos 
comentários. O enfoque pode se dar na diversidade da fauna e da flora; os povos negros do Egito, os reinos antigos, os reis negros de kust, as primeiras a formações e aglomerações em forma de cidade no mundo desenvolvido (a cidade de Kush), as riquezas passadas e contemporâneas do continente africano, as descobertas cientificas do século XXI, sobre a origem do homem neste antigo continente, e as cidades em desenvolvimento e sua reconstrução após o período de colonização europeia na África do século XXI. Em seguida apresentar para apreciação o vídeo da Chimamanda Adichie, "o perigo de uma única

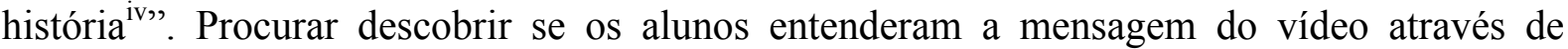
questionamentos, enfatizar a importância de se escutar outros pontos de vista sobre um mesmo assunto para formar uma opinião mais concreta, mais real.

Enfim, a ideia é trabalhar a construção do pertencimento, elevar a autoestima e construir o conhecimento, o professor deve procurar mostrar imagens positivas sobre os negros, os afrodescendentes e sobre a historia do continente africano antes da colonização, o desenvolvimento econômico pós período de colonização. Aproveitar o momento para uma conversa informal sobre o período de colonização europeia no continente africano e as sequelas que ficaram após o processo de independência na maioria dos 54 países africanos etc. Após a execução dos passos anteriores, é chegado o momento de trabalhar com a literatura negra africana e afro-brasileira.

Temos uma infinidade de autores (poetas e escritores) afrodescendentes brasileiros, entre eles: Solano Trindade, Cuti, Candiero etc. O professor Eduardo de Assis Duarte e Maria Nazareth Soares Fonseca, ambos, da Universidade Federal de Minas Gerais- UFMG organizou e lançou recentemente, a coletânea Literatura e Afro-Brasileira, 100 autores do século XVIII ao XXI (2014), e Literatura afro-brasileira: abordagens em sala de aula (2014). O Centro Cultural Humaitá, (Centro de Estudo e Pesquisa da Arte e Cultura Afro-brasileira), Curitiba, Paraná, desde outubro de 2007, realiza um trabalho de resgate e reconstrução da imagem do legado afro no imaginário social da sociedade paranaense. Além dos informativos e revistas (Curitiba afro), criou o Prêmio Orirerê - Cabeças Iluminadas - que traz projetos para aplicação da Lei 10.639/03 e 11.645/08 nas escolas. Tanto este como aquele comporta materiais riquíssimos para o trabalho do professor em sala de aula. Além dos muitos escritores africanos que escrevem em língua portuguesa, por exemplo: Ondijak, Luís Bernardo Honwana, Noêmia de Souza, Mia Couto e muitos outros.

Apresentar aos alunos a poesia negra, neste momento de "ruptura de expectativa" é importante. Como sugestão, iniciar com o poema "Sou Negro a Dione Silva" de Solano Trindade, fazer a apresentação do poeta através de imagens e comentários sobre a obra. 
Chamar a atenção em relação (à semântica) para a postura crítica do poeta Solano Trindade e a mensagem implícita no poema "Sou Negro". O professor pode trabalhar o gênero literário "poema" e suas características, aprofundar o trabalho com a linguagem. Continuar o trabalho de ruptura de expectativa, com outro gênero literário, o "conto" e suas características. Como sugestão - o autor angolano Ondijak, a coletânea "Os da minha rua", (2007) - o conto "Ida ao Nanibe". É um conto juvenil, sobre as lembranças da infância e seu amor de pré-adolescente. É uma leitura leve e agradável. Apresenta algumas palavras do vocabulário africano. Apresentar o autor, onde vive, que é, etc., esclarecer os sentidos dos vocábulos africanos a partir da narrativa (do contexto). O professor deve sempre oportunizar e respeitar o relato dos alunos sobre a narrativa lida, assim o aluno sentirá que tem contribuições a dar no momento da aula. Sugerir a comparação dos textos literários. O poema de Solano Trindade "Sou negro" e o conto a "Ida ao Nanibe" de Ondijak e levantar as semelhanças e diferenças quanto a estrutura textual de cada texto e o registro das conclusões no caderno. Os contos de Ondijak apresentam em sua narrativa lembranças de costumes, tradições festas, e referências a estações do ano, como o inverno (no continente africano, alguns lugares são frios). Nesta etapa, deve-se trabalhar mais textos a fim de criar confiança e segurança. Por exemplo, mais um texto de Ondijak, (2007) "O homem mais magro de Loanda" também da mesma coletânea e "O conto de Escola" de Machado de Assis (1884). Sempre apresentar os autores dos textos, realizar o trabalho de leitura, debate e análise com os contos respectivamente. Levantamento das características do gênero literário e o que mais chama a atenção dos alunos nos dois contos.

Finalizar a etapa e preparar para "o Questionamento do Horizonte de Expectativa", o quarto passo. Nesta etapa apresentar mais um conto de Ondijak da mesma coletânea, "O último carnaval da Vitória" impresso e apresentar a pintura "Carnaval nos arcos" de Heitor dos Prazeres, para uma leitura visual. Apresentar o pintor, escritor, músico e sambista e solicitar a comparação dos dois textos. Explicar que a pintura também é um texto e por que é um texto. A leitura visual oral é uma experiência nova para eles. O conto de Ondijak, apresenta em sua narrativa lembranças de costumes, tradições festas, e referências ao início da presença de soldados estrangeiros em Angola.

Até o momento, o trabalho realizado com textos que conversam com o universo que o aluno traz, sua vivencia e informações diferentes das já conhecidas é profícuo, a curiosidade da maioria dos jovens é ampliada. Essa curiosidade gera uma necessidade de saber mais sobre a cultura africana e afro-brasileira. 
Antes de apresentar textos um pouco mais complexos próprios para a etapa do "questionamento do horizonte de expectativa", o professor pode propor a busca por mais informações sobre a cultura africana e afro-brasileira através palestras com representantes dos movimentos negros, poetas, escritores etc.

Nesta etapa é introduzido os gêneros textuais orais - leitura dramática e palestra e o gênero textual escrito - convite. E mais poetas negros e afrodescendentes brasileiros e africanos devem ser apresentados para o aluno, por exemplo: Sérgio Vaz, poeta engajado na defesa das causas raciais e um dos seus poemas "Magia Negra" (2012, p 44), um belo poema que fala das belezas negras na música, nas artes em geral. Outro poeta, é o Candiero, Zelador Cultural e Presidente do Centro Cultural Humaitá, no Paraná e dois de seus poemas, “Gameleira Branca" (2013, p 21) e "Batuques e Fandangos" (2013, p 20). Poemas que tratam das tradições afro-brasileiras. Explicar o que é, e como fazer uma Leitura dramática. Realizar a leitura dramática e motivar os alunos a fazerem o mesmo com os poemas apresentados. Negociar tempo de ensaios e momento de apresentação etc.,

Como não podemos esquecer que a escola tem um projeto politico pedagógico e que o conhecimento historicamente construído deve ser apresentado aos jovens estudantes, é neste momento, que o trabalho com o gênero textual oral "palestra" e o gênero escrito "convite" e suas características deve ser realizado.

Para concluir esta atividade, os alunos elaboram, juntamente com o(a) professor(a) mediador(a), o convite e enviam ao palestrante. Proporcionar uma liberdade dirigida aos alunos para a realização da palestra e da entrevista.

O professor deve coordenar o processo, mas deixar que os alunos realizem todas as ações necessárias para a realização da palestra. Uma agitação incrível acontecerá durante as aulas, pois este é o momento do "evento" segundo Zuben (1994, p.10).

A quarta etapa, é "o questionamento do horizonte de expectativas". Nesta fase, o professor, após todo o evento propõe fazer uma avaliação junto com os alunos do evento e do processo de aprendizagem até o momento.

Ao fazer a ligação entre o já conhecido e o novo, segundo Bordini e Aguiar (1993), o aluno questiona o que lê e observa o texto com um novo olhar.

\footnotetext{
"A classe exerce sua análise, decidindo quais textos, através de seus temas e construção, exigiram um nível mais alto de reflexão e, diante da descoberta de seus sentidos possíveis, trouxeram um grau maior de satisfação. Supõe-se, portanto, que os textos de melhor realização artística tendem a ser vistos como difíceis num primeiro momento e, devidamente decifrados, a provocar admiração do leitor". (Bordini; Aguiar, 1993, p.90).
} 
É chegado o momento de trabalhar com textos mais complexos como, por exemplo, o conto "nós matamos o cão tinhoso" de Luís Bernardo Honwana (1964) disponível em: jardimdasnacoes.com.br/..doc. O título nos remete a um livro com sete contos, "Dina", "Papa, Cobra, Eu", “As Mãos dos Pretos", "Inventário de Imóveis e Jacentes", "A Velhota" e "Nhinguitimo" e entre eles "Nós Matámos o Cão-Tinhoso". Este é o conto mais longo e tido como principal do livro. Os contos citados tem por objetivo mostrarem através da narrativa feita por crianças, o universo social e cultural moçambicano carregado de racismo poder colonial português. O universo social e cultural moçambicano durante a época colonial. A coletânea apresenta "questões sociais de exploração e de segregação racial, de distinção classe e de educação". O conto parece ser uma metáfora da Historia do Continente Africano. Apresentar o autor moçambicano e após a leitura propiciar o debate sobre a leitura realizada. A contextualização poética, mítica, histórica, teórica, temática e crítica realizada pelo professor nesta etapa e nas que se seguem deve permear todo processo de discussão e debates no trabalho com os alunos em sala de aula.

A última etapa é "a ampliação do horizonte de expectativas": aqui o aluno se posiciona diante do texto de forma consciente e crítica, aceitando ou refutando a ideia implícita no texto e, o que é mais importante, ficando aberto para outras leituras.

\footnotetext{
"Os alunos nessa fase, tomam consciência das alterações e aquisições, obtidas através da experiência com a literatura. Cotejando seu horizonte inicial de expectativas com os interesses atuais, verificam que suas exigências tornaram-se maiores, bem como que sua capacidade de decifrar o que não é conhecido foi aumentada. (Bordini\&Aguiar, 1993, p.90-91).
}

Para essa fase, apresentar para leitura contos complexos, como por exemplo, o conto "Bola com Feitiço", do autor angolano, Uanhenga Xitu, nome Kinbundo do africano de Agostinho André Mendes de Carvalho. A coletânea tem dois contos maravilhosos, o primeiro "mestre Tamoda" que trata da necessidade da ascensão social e da identidade do personagem principal e o segundo conto "Bola com Feitiço" que apresenta um olhar bem particular sobre as transformações ocorridas interior de Angola e as questões lusofônicas da colonização. $\mathrm{O}$ conto desperta muitas curiosidades na maioria dos alunos por que trata do fantástico, da magia, das crenças e tradições africanas e afro-brasileiras, além de ser divertido acompanhar o relato de um jogo entre dois times que fizeram uso da "magia" para vencer a partida de futebol. Observa-se a divisão entre os que aceitam os usos dos feitiços e os que não aceitam é 
uma narração bem humorada, de uma grande confusão que vai envolvendo todos os participantes do jogo.

Este é um conto mais complexo que necessita de amadurecimento para se posicionar diante do texto de forma consciente e crítica, aceitando ou refutando a ideia implícita no texto e, o que é mais importante, ficando aberto para outras leituras. A contextualização poética (apresenta como narrador, o griot - contador de histórias- que conta a partida de futebol e os artifícios criados pelos personagens para vencer a partida), histórica (1974 período em que o poeta da Geração 70, a Geração do Silêncio, começou a contar a história de Angola, a partir das divergências civis após a Independência angolana), a crítica, (a situação de conflito entre os angolanos após a independência, o que faz com que atrase o desenvolvimento de Angola), temática (a obediência ao tema, falar sobre os valores culturais do povo angolano) e teórica. Tais observações devem ser feitas pelo(a) mediador(a) no momento do debate sobre a leitura realizada. A próxima leitura pode ser o fragmento do conto "O último discurso" em Ualalapi de Ungulani Ba Ka Khosa (1990, p.97-125) previsto para leitura.

Como pode se observar há uma gradação de complexidade nos textos apresentados, e a necessidade de um trabalho mais intenso, pois os jovens precisam ser preparados e motivados para o trabalho com a literatura africana e afro-brasileira. E aos poucos vai se construindo o orgulho de pertencimento do aluno, a medida que o mesmo se vê retratado, e do quanto ele é capaz de realizar.

Os textos sugeridos são obras que abordam temas interessantes e que podem trazer para a sala de aula uma discussão calorosa sobre valores e princípios. Requer-se, então, um cuidado especial, pois o professor deve ter bem definido quais valores pretende discutir, e o aluno, por sua vez, deve compreender a importância de uma leitura reflexiva para o seu crescimento como pessoa humana. Cândido afirma ser "a literatura um fator indispensável de humanização":

Entendo aqui por humanização [...] o processo que confirma no homem aqueles traços que reputamos essenciais, como o exercício da reflexão, a aquisição do saber, a boa disposição para com o próximo, o afinamento das emoções, a capacidade de penetrar nos problemas da vida [...] (Cândido, 1995, p.249).

Von Zuben desafia-nos a fazermos do momento da aula "um evento" onde a construção de conhecimento acontece por meio dos embates de vozes e ideias. "O ser humano tem a necessidade primária de buscar o novo, a liberdade de ser. E é neste "espaço de ação" 
que a fala dialógica, as ideias sobre fatos, coisas e pessoas se formam e desenvolvem mais intensamente" (1964, p.10).

O trabalho desenvolvido com a literatura africana e afro-brasileira e acima de tudo com posturas positivas sobre a raça negra mostrará que procurar caminhos alternativos para a formação do sujeito crítico, consciente do seu papel de cidadão e principalmente da sua humanidade é gratificante. Além de satisfazer a Implementação da Lei 10.639/03 em sua obrigatoriedade.

Portanto, cabe a todos e principalmente aos professores, procurarem por caminhos que possibilitem modificar a visão ligeira e superficial que a contemporaneidade do século XXI, está proporcionando à sociedade em geral e muito particularmente aos jovens sobre a Historia e Cultura Africana e Afro-brasileira.

\section{4 - Considerações finais}

As mudanças esperadas, os resultados observados e retratados na concretização de um novo olhar para o "outro", através de atitudes, tratamento com e para este outro, mostra que é possível trabalhar com os jovens contemporâneos, utilizando a literatura como instrumento para formar seres humanos mais sensíveis nas suas relações sociais, mais humanos, e consequentemente mais completos. O homem como um ser social que é, precisa do embate entre ideias e não do embate entre pessoas, para se construir e construir uma sociedade mais tolerante. A literatura em sua plenitude traz para o leitor um mundo, no qual os personagens podem compartilhar sentimentos, atitudes, posturas vivenciadas nas quais nos retratamos, traduzindo nossas expectativas diante da própria realidade. E neste embate dá-se a reflexão e a criação de novas posturas diante da realidade e a humanização do homem segundo Antônio Cândido.

Como sociedade não devemos ficar na margem do rio, observando. É necessário buscar soluções, sejam elas simples ou complexas. Ir além e através do debate e das reflexões com os pares, pensar possibilidades, criar pequenas trilhas e possam ser alargadas pelos caminhantes que por ali quiserem passar.

Estas são as reflexões que apresento com a intenção de colaborar para a implementação da Lei 10.639/03, e assim, respeitar o direito de cada ser humano negro ou afrodescendente em saber a sua historia, a nossa historia, a história das descendências africanas e afro-brasileiras. Um começo de conscientização e reconhecimento sobre a importância do povo africano na formação cultural brasileira. 
Concluindo, este artigo foi produzido a partir de uma releitura do material didático pedagógico criado como consequência do Processo de Formação de Professores da Secretaria de Educação do Estado do Paraná (PDE 2013).

\section{REFERÊNCIAS}

A África que nunca vimos ou que ninguém nos mostra. Disponível em: https://www.youtube.com/watch?v=3vllE0-Xuo0 . Acesso em: 14 out 2013.

ABDALA Jr., B. A literatura, a diferença e a condição intelectual. Revista Brasileira de Literatura Comparada, nº, p19-39, 2006.

ADICHIE. C. $O$ perigo de uma única história. Disponível em: http://www.ted.com/talks/lang/por_br/chimamanda_adichie_the_danger_of_a_single_story.ht ml. Acesso em: 09/04/2013

ASSIS, Machado de. Conto de Escola. disponível em: http://www.acervodigital.unesp.br/bitstream/123456789/18/3/Texto\%20\%20Conto\%20de\%20Escola\%20-\%20Machado\%20de\%20Assis.pdf

BAKHTIN, M. V. Estética da criação verbal. São Paulo: Martins Fontes, 1992. Apud PARANÁ. Diretrizes Curriculares da Educação Básica. Curitiba: SEED, 2009.

BORDINI, M. da G.; AGUIAR, V. T. de. Método Recepcional. In: Literatura: a formação do leitor. Porto Alegre: Mercado Aberto, 1988.

CÂNDIDO, A. A literatura e a formação do homem. Ciência e cultura. São Paulo: v.4, n.9, p.803-809. Set. 1972. Apud PARANÁ, Diretrizes Curriculares da Educação Básica. Curitiba: SEED, p. 57, 2008.

CANDIERO, Zelador Cultural. Revista Curitiba Afro. Curitiba. Paraná. Novembro, 2013, p 20 e 21.

COSSON, R. Letramento literário: teoria e prática. São Paulo: Contexto, 2006

DOLZ, J.; SCHNEUWLY, B.; NOVERRAZ, M. Sequências didáticas para o oral e a escrita: apresentação de um procedimento. In: SCHNEUWLY, B.; DOLZ, J. Gêneros orais e escritos na escola. Tradução: Rojo, R. Campinas: Mercado das Letras, 2004.

DUARTE, Eduardo Assis. (Coord.) Literatura Afro-Brasileira. 100 autores do século XVIII ao XXI. Rio de Janeiro. Ed Pallas. $1^{\text {a }}$ ed. 2013.

DUARTE, Eduardo Assis, (Coord.) Literatura Afro-Brasileira. Abordagens na sala de aula. Rio de Janeiro. Ed Pallas. $1^{\text {a }}$ ed. 2013. 
GEMAA - Grupo de Estudos Multidisciplinares da Ação Afirmativa. (2011) "Ações afirmativas". Disponível em: http://gemaa.iesp.uerj.br/index.php?option $=$ com $k 2 \&$ view $=$ item\&layout $=$ item\&id $=1 \& \mid$ temid $=217$

HONWANA, Luís Bernardo. Nós matámos o cão tinhoso (1964). disponível em: jardimdasnacoes.com.br/.../NÓS-MATÁMOS-O-CÃO-TINHOSO.doc

JAUSS, H. R. A história da literatura como provocação à teoria literária. São Paulo: Ática, 1994. Apud PARANÁ. Diretrizes Curriculares da Educação Básica. Curitiba: SEED, p. 58, 2008.

KHOSA, Ungulani Ba Ka. Ualalapi. Moçambique: Caminho, 1990.

MATSUDA, A. A., HADDAD, E. Proposta de sequências didática e letramento literário. In:

COSSON, R. Letramento literário: teoria e prática. São Paulo: Contexto, 2006.

ONDJAKI. Os da minha rua. Rio de Janeiro: Língua Geral, 2007.

ORIRERÊ, Prêmio. Cabeças Iluminadas. Projetos de aplicação das Leis 10.639/03 e 11.645/08. Paraná, Curitiba: Centro Cultural Humaitá, 2013.

PEIRCE. C. S. Semiótica: Estudos. São Paulo: Perspectiva, 1999.

PRAZERES, Heitor dos. Título: Carnaval nos arcos. Técnica: óleo sobre tela. Ano:1961. Disponível em: http://www.riocomela.com.br/index.php/page/105/?cat=-1.Acesso em: 18 set 2013.

SANTOS, R. O. Uma reflexão sobre o desenvolvimento de posturas positivas em relação à etnia negra nas salas de aula, através da Literatura afro brasileira e africana. SEED.PR. PDE 2013.

SEDIKIDES, C.; GREGG. A. P. "Portraits of the self." In: M. A. HOGG; J. COOPER (Eds.). Sage handbook of social psychology. Londres: Sage Publications. 2003, p. 110-138.

TRINDADE, S. História de vida. D Disponível em: http://www.quilombhoje.com.br/solano/solanotrindade.htm. Acesso em: 18 /09 /2013.

VAZ, Sérgio. Magia Negra. Disponível em: http://educação-etnicorracial.blogsport.com.br/ Acesso em 10 Novembro 2013.

VYGOTSKY, L. S. A formação social da mente: o desenvolvimento dos processos psicológicos superiores. $6^{\mathrm{a}}$ ed. São Paulo: Martins Fontes, 1998.

XITU, UANHENGA. Bola com Feitiço. Contos. Lisboa. Biblioteca Editores Independentes, Edições Cotovia, Ltda. 2008.

ZUBEN, N. A. Sala de Aula: Da angústia de labirinto à fundação da liberdade. In MORAIS, R. de (Org.). Sala de Aula. Que espaço é esse? 10ª ed. Campinas: Papirus, 1994. 


\footnotetext{
${ }^{\text {i }}$ Professora da Rede Estadual da Secretaria de Educação do Estado do Paraná (SEED).

${ }^{i i}$ Disponível em: https://www.youtube.com/watch?v=3vllE0-Xuo0

iii Disponível no blog: https://africavidaecor.wordpress.com/

ii Disponível em: https://www.youtube.com/watch?v=3vllE0-Xuo0

iii Disponível no blog: https://africavidaecor.wordpress.com/

iv Disponível em:

http://www.ted.com/talks/chimamanda_adichie the_danger_of_a single_story?language $=\mathrm{pt}-$ $\underline{\text { br }}$
} 